\title{
The Construction of an Environmental Management Model Based on Sustainability Indicators on a Higher Education Institution in Mexico
}

\author{
Efraín C. Nieblas-Ortiz ${ }^{1}$, José L. Arcos-Vega ${ }^{1} \&$ Juan J. Sevilla-García ${ }^{1}$ \\ ${ }^{1}$ Engineering Institute, Universidad Autónoma de Baja California, Baja California, México \\ Correspondence: Juan J. Sevilla-García, Engineering Institute, Universidad Autónoma de Baja California, Baja \\ California, México. Tel: 1-686-566-4150. E-mail: jsevilla@uabc.edu.mx
}

Received: November 16, 2016

Accepted: November 24, 2016 Online Published: December 25, 2016

doi:10.5539/hes.v7n1p15

URL: http://dx.doi.org/10.5539/hes.v7n1p15

\begin{abstract}
Without depreciating the importance of environmental regulations directed to university environmental managements systems in this country, nowadays, the instruments of international importance like the Sustainable Development Goals or ONU's 2030 Agenda; as well as those of domestic nature, like sustainability indicators proposed by the Mexican Consortium of University Environmental Programs for Sustainable Development (Complexus) to measure the contribution of Higher Education Institutions to sustainability (HES), and those indicated by the Interinstitutional Committees for Higher Education Evaluation (CIEES) and the organisms that make up the Council for the Accreditation of Higher Education (COPAES), pose great challenges to universities as institutions that form human capital who are aware of their relationship with nature.

This forces the university to rebuild its sustainability view based on the premise that all activities relative to its substantive functions are related to socio-environmental issues on the region.

Due to this, Universidad Autónoma de Baja California (UABC), coherent to its environmental management institutional plan, defined in the Institutional Development Plan, must structure a series of indicators which allow the evaluation of its sustainability policy.

The purpose of this research is to develop an environmental management model bound to performance indicators that allow UABC to progressively assume the task of answering the environmental challenges posed by its surroundings, trying to strengthen its curricula, in order for its programs to be more relevant and appropriate with social, economic, cultural, and environmental priorities.
\end{abstract}

Keywords: management, indicators, environment

\section{Introduction}

World concerns for environmental issues origin from recent public perception, who recognized, since the seventies decade of the last century, that dominant social and economic development models imply a growing risk of environmental deterioration. This perception forced the United Nations (UN) to create the United Nations Environmental Program (UNEP), which was a turning point and started the development of environmental public policies, and strengthened environmental regulations in almost all countries in the world.

Influenced by external context, a series of constitutional changes were structured in this country, which influenced policies, programs, regulations, and government institutions; first, on a national scale, then, on state and local scale.

Nowadays, Mexico has a wide institutional and regulation base, aimed to a new development model that has sustainability as premise, based on internationally accepted guiding principles, like a person's right to a healthy environment for his well being and development, among others.

On the other hand, for many years, UABC has had as priority to apply an institutional policy that allows orientating the environmental management in an exercise of its main functions of teaching, research, and culture and services extension, focused in guaranteeing that the institutional development has a clear perspective of sustainability and integration.

Is because of this that UABC Institutional Development Plan 2015-2019 establishes University Social Responsibility as a central concept of outmost relevance. At the same time, it enhances Environmental 
Management all the way to Institutional Program, with which the environment and natural resources protection culture in university functions will be promoted (UABC, 2015).

A series of strategies come from this institutional program, of which the establishment of an Environmental Management Institutional Plan stands out, a fact that sets a precedent in the institution's life; never before have the sustainability and environmental preoccupations been on a scale of institutional plan.

\section{Antecedents}

The program and regulatory framework that supports and boosts the University interest in creating and implementing a university environmental program has its antecedents in the conjunction of a series of international and national efforts in the higher education area.

In example, maybe the first antecedent dates back to the Talloires Declaration, France, about university and environment. Such document is a declaration for higher education institutions to take world leadership in the development, creation, support, and maintenance of sustainability. Nowadays, the University Leaders for a Sustainable Future (1990), functions as a ministry for the Declaration management. Until October 2008, 378 institutions in 50 countries, in 5 continents had signed this declaration.

Additionally, the Declaration of Principles of the Higher Education World Conference held in Paris, France; from October 5 to 9, 1998; among other principles, it outlines the construction of an open space for higher education to promote permanent learning, as well as opportunities of individual development and social mobility, in order to train citizens that participate actively in society, and to promote the strengthening of endogen capacities and consolidation in a framework of human rights justice, sustainable development, democracy, and peace (UNESCO, 1998).

Regarding national policies for higher education development, those proposed by the National Association of Universities and Higher Education Institutions (ANUIES in Spanish) stands out, Higher Education in the XXI Century: Strategic Development Lines, which proposes the view of higher education system until year 2020, starting from a series of guiding postulates that describe the system's desirable situation.

Among the Guiding Postulates that ANUIES propose, the Third Postulate stands out, regarding the appropriateness of higher education in relation to the country needs, which defines Teaching, research, and dissemination must be planned and carried out, aiming to solve environment issues in every HEI. Their nature as a space to cultivate knowledge makes the HES have a relevant role in identifying needs, in a creative view framework of sustainable development in the country, in the long term (Malo, 2000).

On the other side, Mexico Strategy with Quality Education, of the National Development Plan 2013-2018 proposes To develop science, technology, and innovation in order to achieve an economic and social sustainable progress. Meanwhile, Mexico Strategy, Prosperous, aims to Promote and guide a facilitating a green growth that preservesour natural heritage (Mexican Government, 2013).

The Mexican Consortium of University Environmental Programs for Sustained Development in the United Nations Decade of Education for Sustainable Development 2005-2014, recognizes that the universities play an essential role to contribute for the prevention and solution of environmental issues and to overcome sustainability challenges; it also declares that two of the challenges that HEI must assume in their sustainability promoter role are coherence, setting as example the campus interior, and appropriateness, including sustainability principles in their academic and governance and management functions, emphasizing their social commitment (Complexus, 2006).

Nowadays, in UABC does not have an integral environment management model that complies with national and international requirements; as a result, it has only promoted compliance of ISO 9001: 2008, ISO 14001: 2004, Clean Industry, granted by the Federal Environmental Protection Agency (PROFEPA), in some of its facilities and processes; this represents a challenge for establishing an environmental management model that incorporates a guide, coordinated by an institutional dependency and continuous grading of its results, based on the definition an implementation of its environmental management indicators.

\section{Environmental Management Systems}

In an international scale, environmental issues in university management and curricula have been around for decades, with different grades of deepness, space, and success in its implementation. Experiences revised denote that the treatment given to environmental issues includes informative treatment of purely ecologic topics in order to reach this subjecton a global scale, reaching for curricular and university management aspects, but, above all, with a participative strategy. 
There are constantly more universities that have incorporated the environment variable in their management, teaching, research, and, in general, in university life. The reasons why universities have incurred in pro environmental actions are: of internal nature, economizing costs, an increase in labor security and hygiene, the demands from some members of the university, and the promotion of good practices; of external nature, the compliance with environmental legislations, government or financial institutions requirements and, to a lesser extent, pressure from environmental groups (Benayas, 2004).

Perhaps one of the examples that stands out the most in the international efforts that synthetize the interest of HEI for sustainability and environmental management will take us to the core of the Spanish Universities Dean Conference (CRUE), which, in 2004, formed a work group for environmental quality and sustainable development, to promote sustainability actions in Spanish universities.

Since July 2008, this group evolved into Sectoral Agency for Environmental Quality, Sustainable Development, and Risk Prevention in universities (CADEP). The number of joining universities in this agency is 65, which proves a great interest in sustainability policies in almost all Spanish universities.

The group for "University sustainability evaluation" of the Sectoral Agency for Environmental Quality, Sustainable Development, and Risk Prevention in universities (CADEP) of CRUE has been working since 2007 in the systematic research of sustainability initiatives in Spanish universities. Between 2010 and 2011, it has developed the research-Evaluation of university sustainability policies as facilitators for developing campus of international excellence (CEI), in which areas and indicators have been defined to measure the contribution of Spanish universities to sustainability. These indicators constitute an evaluative framework in the advance grade of sustainability policies, making progress more viable for the university community and society (Benayas et al., 2010).

Among other important experiences, these stand out: In the United States and Canada, the main evaluation system for university sustainability is called STARS: Sustainability Tracking, Assessment and Rating System, and is promoted by the Association for the Advancement of Sustainability in Higher Education (AASHE).

Additionally, in the United Kingdom exist diverse evaluation systems for university sustainability, promoted by different organizations: People and Planet, a student association promotes Green League for Universities; the Environmental Association of Universities and Colleges (EAUC), promotes the Green Gowns Awards and Universities that Count, among others.

Since 2009, in France, there is an obligation for higher education institutions to create a Green Plan, with which they can request a quality seal based on sustainable development criteria. It is worth noting that the Dutch association for universities and environment (DHO) promotes, since 2001, the AISHE evaluation program: Auditing Instrument for Sustainability at Higher Education.

On a national scale, sustainability in higher education institutions in Mexico is based on the premise that none of the knowledge areas is apart from socio-environmental issues. It is considered that higher education institutions will be capable of responding to such challenges when they recognize the need for an environmental perspective that goes through all directions in HEI substantive functions and daily work.

Subsequently, higher education institutions are seen as institutions with a great potential to organically participate in the environmental transformation of society, which has been happening for some years, and to contribute in searching for alternatives to the critical environmental condition. It is foreseen that: Contribution of HEI to solving and preventing environmental deterioration, along with their support to create desirable development scenarios, will necessarily go through current knowledge creation ways, in which ANUIES, government dependencies, higher education institutions, among others, have participated (Bravo, 2012).

Regarding this, it is worth mentioning that Mexico has created an HEI network in favor of promoting Environmental Education for Sustainable Societies (EASS), called COMPLEXUS. In the cooperation agreement, which created this committee, a series of objectives have been outlined, which, despite the time that has passed, are still valid and maintain their guiding function aiming to sustainability; such objectives have been introduced in the fundamental base of many Institutional Environmental Plans and Programs (Ortiz \& Ayala, 2013).

It is worth noting that the Interinstitutional Committees for Higher Education Evaluation (CIEES) has developed an evaluation model for institutional administration and management to award quality, which proposes a series of indicators, in example, evidence of policy implementation of a quality management system to an institutional level and the existence of a certified ISO 9001: 2008 and IWA-2 system, that include: Academic processes, human resources, finances, school management and outreach, and, when appropriate, a management system for 
environmental aspects via certification using ISO14000 and ISO18001 (Corrales, de la Garza, Gutiérrez, \& Arcos, 2012).

Furthermore, a series of national institutions have promoted the compliance of Regulation 26000, which is the Guide for compliance with Social Responsibility as part of the account ability report to society from the IES, both private and public areas (ISO, 2010).

Moreover, within the Mexican System of Evaluation and Accreditation, specifically in relation to educational programs offered by HEI, the organisms that make up the Council for the Accreditation of Higher Education (COPAES for its acronym in Spanish) contemplate explicitly the need to address issues related to the environment. In the terms of reference of the Council for Accreditation of Engineering Education (CACEI), there is a mention of the existence of complementary courses which include among other areas, sustainable development and environmental care (CACEI, 2016). Meanwhile the Committee for Program Evaluation of Pedagogy and Education (CEPPE) states in its framework for the accreditation of educational programs, the need to include issues associated with commitment to environmental conservation and socio-cultural (CEPPE, 2016). Similarly, in the Accreditation Council of Communication (CONAC) define the need for curricula transversal contents, where among other issues to be addressed commitment to the preservation of the environment is found (CONAC, 2016).

As seen in previous cases, they all reflected the intention that those associated with the sustainable development and environment issues form part of the preparation of graduates in different disciplines in Mexican HEI.

\section{Sustainability Indicators}

Regarding the utility of environmental indicators, it is widely accepted that they play an important role as basic information tools for elaborating reports about the environment condition, especially in relation to process tracking in the evolution of environmental policies and the integration of environmental aspects in different sectorial policies.

There are many initiatives from many different international institutions, which have promoted the development environmental indicators. Among others: The United Nations Committee for Sustainable Development, the Organization for Cooperation and Economic Development, the European Union Commission and its Statistics Bureau, and the Environment European Agency. A series of specific institutions from many countries should be added to these (Aguirre, 2002).

Environmental indicators summarize a lot of environmental data into quantity-limited key information. Thus, assuring a quick evaluation of the main improvements and weak spots in environmental protection of an organization, for those that shall make decisions. Furthermore, they allow for deciding quantifiable environmental objectives that can be used to measure the success or failure of any actions.

The Latin-American Universities are progressively accepting the task of responding to their country environmental challenges. They are trying to assure that environmental considerations are included, in example, in the curricula, the sustained consumption of energy, water management, acquisition processes, and residue management. They are also researching deeper into a bigger environmental innovation, and; the strengthening of cooperation with the private sector and communities to make their programs more relevant and beneficial to meet the society needs and economic, environmental, and social priorities.

On December 2013, the First Latin-American Forum of Universities and Sustainability was held in Viña del Mar (Chile), summoned by the Alliance of Ibero-American University Networks for Sustainability and the Environment (ARIUSA), the Environmental Education Network for Latin America and the Caribbean (RFA-ALC), and the Latin American Chapter of Universities World Alliance for Environment and Sustainability (GUPES-LA). This meeting served as a starting point for the Indicators Network of University Sustainability (RISU).

An evaluation tool has finally been designed together with 114 indicators distributed in 11 topics or areas of the possible implementation of sustainability in universities: Sustainability policy (15 indicators), Sensitization and participation (12 indicators), Socio-environmental responsibility (10 indicators), Teaching (13 indicators), Research and transference (13 indicators), Urban planning and biodiversity ( 7 indicators), Energy (10 indicators), Water (10 indicators), Mobility ( 8 indicators), Residue (11 indicators), Responsible hiring (5 indicators) (Benayas, 2013).

Between years 2001 and 2013, COMPLEXUS (2013) developed a proposal of Indicators to Measure the Contribution of Higher Education Institutions to Sustainability. This proposal includes 21 indicators grouped 
into 5 areas: Institutional Identity (5 indicators), Education (6 indicators), Research (4 indicators), Reach and Diffusion (3 indicators), and Outreach (3 indicators).

\section{UABC Environmental Management Model}

The proposed model aims to strengthen institutional identity and the sense of social responsibility from an environmental and sustainable development perspective, through activities that promote the joining of efforts, to establish innovative projects for environmental compliance, as well as an institutional operation coherent with academic and social preoccupations that significantly diminishes the environmental impact of its activities, thus assuming an important leadership through a bigger commitment to its local, regional, national, and global social surroundings (Universidad Autónoma de Baja California, 2015).

The Environmental Management Institutional Plan will be formed by strategic programs that incorporate, via institutional instruments, environmental criteria in the University daily operations, in such a way that its environmental performance improves over time, contributing to positive behaviors in the university community and society.

While facing a rising preoccupation in the university community to define an environmental policy for sustainability, a few doubts appear: How should the model defined by the University be in order to inspire an environmental-friendly economic and social development, and sustainable management of natural resources? and, How can it create a bigger impact in the campus exterior and interior through environmental programs promoted by UABC with a high sense of social responsibility?

Due to this, it is important to make the most of this university reflection space, in order to propose the construction and implementation of the environmental university policy that strengthens institutional identity from a sustainable development perspective. In order to provide it with instruments, it will be necessary to incorporate it to the same level of commitment and importance that the substantial and adjective functions of our University enjoy, only then can the intended impact be achieved. This implies to rethink the means and administration and operation processes, like those of knowledge generation and transmission, and those relative to diffusion and communication.

Thus, the environmental policy proposed for UABC should incorporate as guiding axis: 1) Environment compliance management, 2) Development of a solid environmental culture, 3) Education and research for sustainability, and 4) Development of compliance indicators and permanent objectives and goals evaluation. See Figure 1.

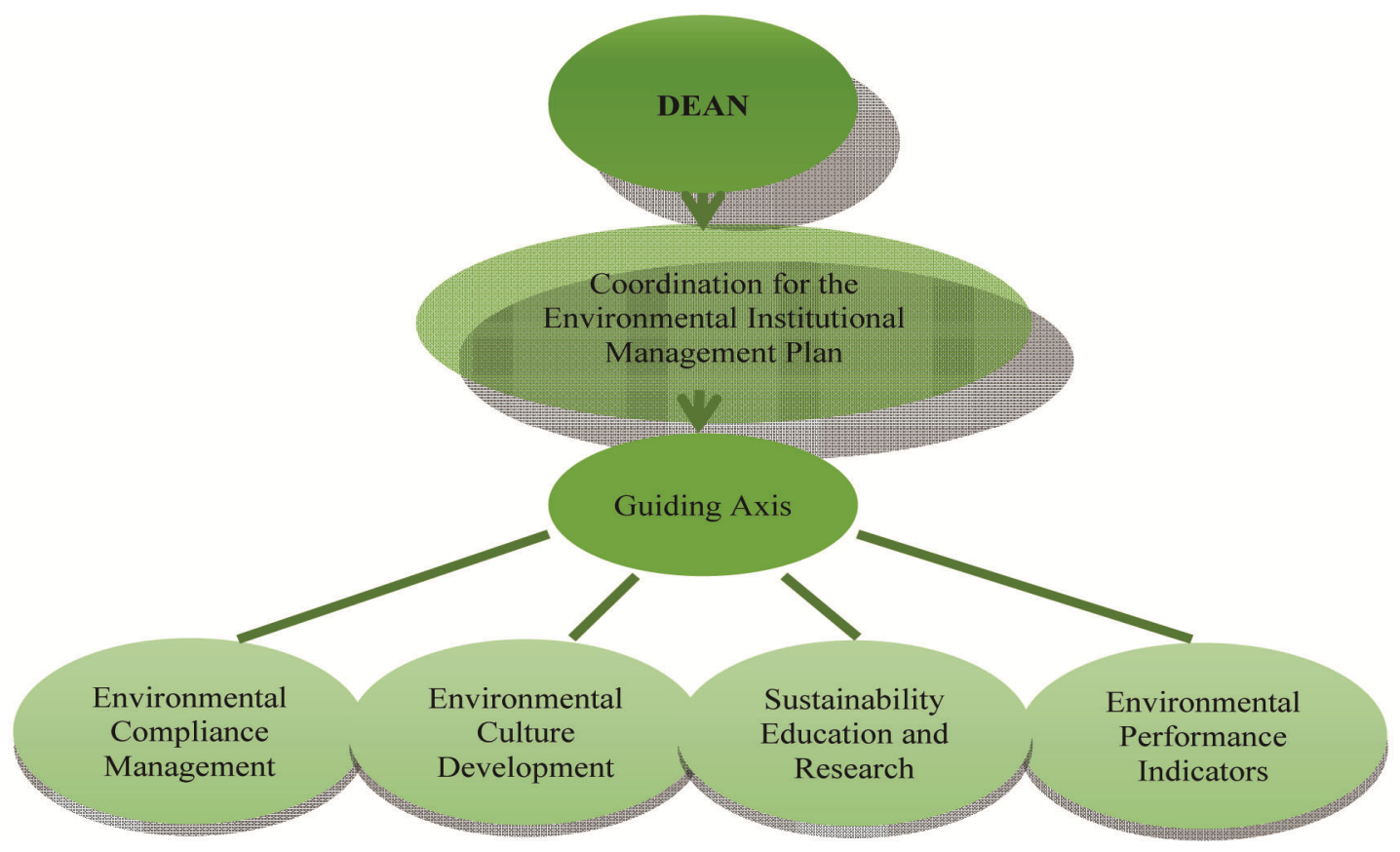

Figure 1. Environmental management university model 
This makes us rethink the way we plan and constitute the campus, the way we move, the way we use water, the means to obtain and use energy, and the contexts that define the communication of our achievements.

\subsection{Guiding Axis 1: Environmental Compliance Management}

Management of environmental legal compliance will be constituted by strategic programs that incorporate, via diverse institutional instruments, environmental criteria in the daily and operative University functions in a way that its performance will improve over time, thus promoting positive behaviors in society and university community in their surroundings.

This guiding axis is formed by five strategic programs: Water re-use and efficient use, energy efficient and rational use, responsible use of materials and equipment, integral residue management, and legal compliance and certifications.

\subsection{Guiding Axis 2: Environmental Culture Development}

UABC does not only play an important role regarding the development of competent students, but also has the moral and ethical obligation of preserving ecosystems through pre-established cultural programs.

The key for success in this program will be based on the definition of objectives and goals through this institution's awareness and internal communication process, which is intended to orientate communication to a change of conscience focused to achieving a cultural change among the university community.

This guiding axis includes three strategic programs: promotion and consolidation of environmental culture, permanent training, and effective communication.

\subsection{Guiding Axis 3: Sustainability Education and Research}

Through this guiding axis, the University must strengthen the environmental management systems, organically associated to essential teaching, research, and extension functions, to improve its environmental performance, with the participation of academic communities as a whole. This works as a voluntary way of assuming the institution's social responsibility, coherent to the education of university students and the obligations of society; it may also be used to reach sustainability (COMPLEXUS, 2006).

\subsection{Guiding Axis 4: Environmental Development Indicators}

Planning, tracking, and evaluation of the Environmental Management Institutional Plan require a solid indicators system that allows to convert pure data into added and synthetic information, comprehensible for all the university community, but, especially, for the people making decisions.

The information generated based on performance indicators must adequate to the University requirements and priorities. In addition, it must be evident enough to reflect important changes in the environmental impacts generated by the institution (Secretaria del Medio Ambiente y Recursos Naturales, 2010).

A performance indicator is the specific expression that provides information about measurable results for the management done by the organization on its environmental aspects (ISO, 2004).

Without further ado, a series of indicators related to important environmental aspects are now presented, which the University must develop when implementing its environmental management model.

\subsubsection{Indicators of Efficient Water Use}

Water use, daily water used by students, student restrooms, water-economizer restrooms, rain water, residue-water re use, decrease of water volume on first use.

\subsubsection{Indicators of Efficient Energy Use}

Total fuel consumption, fuel consumption per vehicle, maximum rate of electricity consumption in facilities, decrease of electricity consumption, rate of electricity consumption by students, bike lane kilometers, number of students per vehicle (shared transport).

\subsubsection{Indicators of Green Purchases Aspects}

Lower impact stationary, daily paper consumption, photocopier use, toner consumption, electronic signature, forest certificated furniture.

\subsubsection{Indicators of Responsible Consumption Aspects in Offices}

Paper consumption per employee, daily paper consumption, photocopier use, toner consumption, electronic signature, and electronic documents. 


\subsubsection{Indicators for Integral Management of Residues}

Solid residues generated by students, valued solid residues, recycled paper, dangerous residues generated by students, valued dangerous residues, co-processed residues, progressive decrease of confined residues.

\subsubsection{Education Indicators}

Curricula that have incorporated the environmental perspective and sustainability, classes offered on environmental topics and sustainability, training and updating strategies for teachers to strengthen their environmental and sustainability perspective on the curricula, students that have taken classes that address environmental and sustainability topics, professors that teach environmental topics.

\subsubsection{Research Indicators}

Number of academic bodies orientated to environmental and sustainability aspects, general knowledge lines dedicated to the environment and sustainability, scientific publications, postgraduate studies orientated to the environment and sustainable development, research projects of internal invitation, research projects of external invitation, research projects of outreach agreements, social impact projects.

\subsubsection{Extension Indicators}

Student percentage on training classes, environmental programs through media like T.V., radio and radio, publications on magazines, gazettes, newspapers, dedicated to the environment and sustainability, forums, conferences, workshops, courses, and diplomats of an environmental perspective, as well as the number of participators, number of environmental triptychs distributed in artistic and cultural presentations, students participating as environmental promoters, journalism publications.

As expressed before, this is all a compendium of possible indicators of environmental performance; nonetheless, depending on the capacity and resources that the University grants to the Environmental Management Institutional Plan, the development and implementation of indicators may be limited, on its first phase, only to the most relevant aspects, and be increased gradually on subsequent phases.

\section{Conclusions}

The benefits of environmental performance indicators proposed by different national and international institutions represent a platform or line on which the development and implementation of those defined by $\mathrm{UABC}$ can be formed, in compliance with its institutional environmental policy.

The formulation and description of the environmental management model indicators represent a UABC environmental performance and can be interpreted as the measurable results of the environmental management system, regarding the control of the organization environmental aspects, based on its environmental policy with an Environmental Management Institutional Plan.

Establishing entrance filters, processes and exit filters when elaborating a good general diagnosis of the current university condition regarding environmental performance. A definition of the policy: objectives and goals based on a solid environmental management system, and a definition of an indicators system: they will be the main base for implementing periodic tracking and evaluation processes that measure the reach and success of the Environmental Management Institutional Plan.

Another challenge is the transition to Regulations 14001: 2015, recognized internationally, which represent the changes on the quality management systems in the prior version, and which is also a complement to reach Regulation 26000 of social responsibility for public organizations in the country.

\section{References}

Aguirre, M. A. (2002). Los sistemas de indicadores ambientales y su papel en la información e integración del medio ambiente. I Congreso de Ingeniería Civil, Territorio y Medio Ambiente, Madrid: España.

Association of University Leaders for a Sustainable Future. (1990). Talloires Declaration. Retrieved from http://www.ulsf.org/programs_talloires.html

Benayas, J. (2004). La ambientalización de los campus universitarios. El caso de la Universidad Autónoma de Madrid III. Congreso Andaluz de Educación Ambiental, Sevilla: Consejería de Educación de la Junta de Andalucía.

Benayas, J. (2013). Proyecto RISU: Definición de indicadores para la evaluación de las políticas de sustentabilidad en universidades latinoamericanas. Reunión de la Red de Indicadores de Sostenibilidad en las Universidades, Lima, Perú. 
Benayas, J. et al. (2010). Evaluación de las políticas universitarias de sostenibilidad como facilitadoras para el desarrollo de los campus de excelencia internacional. Conferencia de Rectores de las Universidades Españolas, Ministerio de Educación, Madrid.

Bravo, M. T. (2012). Los planes ambientales institucionales en la educación superior en México. Mexico: Semarnat.

Comité para la Evaluación de Programas de Pedagogía y Educación. (2016). Marco de Referencia del CEPPE para la Acreditación de Programas Universitarios. México: Autor.

Consejo de Acreditación de la Comunicación. (2016). Marco de Referencia del CONAC. México: Autor.

Consejo para la Acreditación de la Enseñanza de la Ingeniería. (2016). Marco de Referencia 2018 del CACEI en el Contexto Internacional. Mexico: Autor.

Consorcio Mexicano para Programas Ambientales Universitarios para el Desarrollo Sustentable (Complexus). (2006). Declaración. VI Reunión Anual, Saltillo: Universidad Autónoma de Coahuila.

Consorcio Mexicano para Programas Ambientales Universitarios para el Desarrollo Sustentable (Complexus). (2013). Indicadores para medir la contribución de las Instituciones de Educación Superior a la sustentabilidad. Guanajuato: Universidad de Guanajuato.

Corrales, V., de la Garza, J., Gutiérrez, E., \& Arcos, J. L. (2012). Reconocimiento de la calidad de las instituciones de educación superior. México: Universidad Autónoma de Sinaloa.

Gobierno de la República. (2013). Plan Nacional de Desarrollo 2013-2018. Retrieved January 23, 2016, from http://pnd.gob.mx

International Standarization Organization. (2004). Norma Internacional ISO 14001: 2004. Sistemas de gestión ambiental-Requisitos con orientación para su uso. México: Autor.

International Standarization Organization. (2010). Norma internacional ISO 26000: 2010. Guía de responsabilidad social. México: Autor.

Malo, S. (2000). La educación superior en el siglo XXI: Líneas estratégicas para su desarrollo. Una propuesta de la ANUIES. Revista de la Educación Superior, 113(29), 1-8.

Ortiz, E. B., \& Ayala, R. I. (2013). Hacia las Sociedades Sustentables. Notas en torno a procesos innovadores de educación y de investigación. Indicadores para medir la contribución de las instituciones de educación superior a la sustentabilidad. Guanajuato: Universidad de Guanajuato.

Secretaria del Medio Ambiente y Recursos Naturales. (2010). Guía para la implementación de los sistemas de manejo ambiental en la administración pública federal. México: Autor.

UNESCO. (1998). Conferencia mundial sobre la educación superior. La educación superior en el siglo XXI: Visión $y$ acción. Retrieved January 20, 2016, from http://www.unesco.org/education/educprog/wche/declaration_spa.htm

Universidad Autónoma de Baja California. (2015). Plan de Desarrollo Institucional 2015-2019. Mexicali: Autor.

\section{Copyrights}

Copyright for this article is retained by the author(s), with first publication rights granted to the journal.

This is an open-access article distributed under the terms and conditions of the Creative Commons Attribution license (http://creativecommons.org/licenses/by/4.0/). 